\title{
Effect of intertrial interval on variable-interval discrete-trial barpressing
}

\author{
MARK D. HOLDER \\ Memorial University of Newfoundland, Newfoundland, Canada \\ and \\ SETH ROBERTS \\ University of California, Berkeley, California
}

\begin{abstract}
In seven experiments, an effect of the intertrial interval (ITI) duration on barpressing by rats was studied. A stimulus signaled a 15-sec variable-interval trial. The first response after the interval elapsed turned the stimulus off and was rewarded with food. Trials were separated by long (about $300 \mathrm{sec}$ ) or short (about $10 \mathrm{sec}$ ) ITIs. A within-subjects design established that response rate on trials after long ITIs was lower than that after short ITIs (Experiments 1 and 3-7). The effect was not cumulative (the effect of one and five consecutive short ITIs was the same). Response rate after short and long ITIs was the same when a between-subjects design was used (Experiment 2). Response rate was higher after 160-sec ITIs than after 300-sec ITIs, suggesting that the ITI duration at which all longer ITIs are treated the same (i.e., the upper limit) is greater than $160 \mathrm{sec}$ (Experiment 3). When food, the trial stimulus, a novel stimulus, or a familiar stimulus never paired with food, was presented $10 \mathrm{sec}$ before the next trial during some of the long ITIs, response rate on the next trial was similar to that found after 10-sec ITIs (Experiments 4-6). This similarity suggested that these events could mark the start of the ITT. However, the familiar stimulus did so only when it reliably predicted that the next trial would occur after a short interval. The effect of ITI duration on responding was apparently attributable to response latency. Response latency was greater after long ITIs, but once responding began, it was similar after long and short ITIs (Experiment 7).
\end{abstract}

Several studies have shown that animals are sensitive to durations of intervals between trials. For example, in habituation studies, trials separated by relatively short durations produce faster habituation during acquisition and faster extinction in subsequent nonreinforced periods than do trials separated by relatively long durations (Davis, 1970). In studies of spontaneous recovery, a long intertrial interval (IT) during the extinction phase produces more responding than a short ITI (Peeke \& Peeke, 1972). The role of the ITI in autoshaping has been extensively studied, and it has been found that, in general, decreasing the ITI increases the number of trials until the first conditioned response is observed (e.g., Gibbon, Baldock, Locurto, Gold, \& Terrace, 1977; Terrace, Gibbon, Farrell, \& Baldock, 1975). Studies of behavioral contrast have found that as the ITI increases, or as the duration of a nonreinforced stimulus increases, responding dur-

This work was supported by National Science Foundation Grant BNS $79-00839$ and National institute of Mental Health Grant 1 R01 MH383358 01. Mark Holder held a postgraduate fellowship from the Natural Sciences and Engineering Research Council of Canada while he conducted the research and was supported by NSERC Grant A1221 during some of the preparation of the manuscript. The authors thank Peter Killeen for his encouragement and helpful comments. All correspondence should be sent to Mark Holder, Department of Psychology, Memorial University of Newfoundland, St. John's, Newfoundland A1B 3X9, Canada. ing a reinforced stimulus increases (Bloomfield, 1967; Taus \& Hearst, 1970; Wilton \& Clements, 1971). The effect of the ITI is not limited to a specific procedure, species, or dependent measure. For example, Stein, Sidman, and Brady (1958) found that when the ITI was increased, conditioned suppression, as measured by barpressing, increased. Other examples of increases in performance following increases in the ITI include tasteaversion learning in rats (Domjan, 1980) and running responses in rats (Rothkopf, 1955).

Different theories have been employed to explain the increase in responding after increases in the ITI. One theory, developed by Amsel and Roussel (1952), was based on frustration, and was used by Amsel (1967) to explain increased responding in behavioral contrast. The effect of the ITI could be similarly explained (Mackintosh, Little, \& Lord, 1972). Increases in the ITI, a period of no reinforcement, increase frustration and result in an unconditioned increase in responding. A second group of theories was designed to account for the ITI effect in autoshaping (Gibbon \& Balsam, 1981; Jenkins, Barnes, \& Barrera, 1981). These theories assume that the overall time between unconditioned stimuli (USs) is measured by animals and compared with the time between USs during the conditioned stimulus (CS). This comparison determines performance. As the overall time between USs decreases, performance decreases. 
The present experiments employed trials separated by short (10 or $20 \mathrm{sec}$ plus a small variable amount) and long ( 200 or $300 \mathrm{sec}$ plus a small variable amount) ITIs. Barpressing was measured as a function of the duration of the preceding ITI. In all seven experiments, rats were reinforced with food for pressing a bar on a variable-interval schedule of $15 \mathrm{sec}$ during discrete trials signaled by light or sound. These experiments were designed to demonstrate an ITI effect with a new procedure, and to examine some of the factors that underlie this effect. If performance increases as the duration of the nonreinforced ITI increases (Amsel \& Roussel, 1952; Gibbon \& Balsam, 1981; Jenkins et al., 1981), barpressing rates should be higher after longer ITIs. Of course, the theories discussed above were developed to explain data from procedures that differed in several ways from those used here. Some studies that used procedures roughly similar to those used here have reported an inverse relationship between the rate of responding and the time since the last reinforcer. For example, Allen (1980) found that the general activity of thirsty pigeons was greatest immediately after $50-\mathrm{sec}$ access to water, and that this activity decreased over time. Killeen, Hanson, and Osborne (1978) found similar results with hungry pigeons and food. These results have been explained by theories based on arousal or incentives (Killeen, 1979, 1982). Basically, reinforcers increase arousal levels, which in turn increase behavior. This arousal decays over time. After reinforcement, increases in a variety of behaviors (e.g., gnawing, eating, keypecking, and copulation) have been found in a variety of animals (e.g., rats, pigeons, cows, and humans) (see Killeen, 1979, p. 34).

\section{EXPERIMENT 1 BASIC EFFECT OF ITI DURATION ON BARPRESSING}

Experiment 1 was designed to determine the effects of different durations of ITI on barpressing. Responding during a trial was measured as a function of the five preceding ITIs. Conditioning theories that account for ITI effects in autoshaping claim that performance is determined by the average of several preceding ITIs, rather than by only the immediately preceding feeding and the onset of the US (Gibbon \& Balsam, 1981; Jenkins, 1984; Jenkins et al., 1981). For example, if the average of several preceding ITIs is $60 \mathrm{sec}$, but the immediately preceding ITI was $15 \mathrm{sec}$, then performance, which is little affected by the single 15 -sec ITI, can be predicted by the average $60-\mathrm{sec}$ ITI. The arousal theory described by Killeen (1979, 1982) also claims that performance is a function of several preceding ITIs. On the other hand, frustration theory can explain contrast effects resulting from a single ITI.

By measuring responding as a function of the five most recent ITIs, Experiment 1 could determine if animals were sensitive only to the most recent ITI, or if they were sensitive to an average of several ITIs, including the most recent. For example, if responding is governed by only the most recent ITI, then responding should be the same on all trials preceded by ITIs of the same duration, regardless of the duration of earlier ITIs.

\section{Method}

Subjects and Apparatus. The subjects were 8 albino male rats (Charles River CD, born in the U.C. Berkeley laboratory colony), about 110 days old at the start of the experiment. All rats had had extensive prior experience (Holder \& Roberts, 1985, Experiment 2) with a procedure involving instrumental trials (20-sec fixed-interval, discrete trials) intermingled with classical conditioning trials (forward pairing, backward pairing, and extinction trials). Throughout the experiment, after each daily session, each rat was fed $13 \mathrm{~g}$ of Purina Rat Chow mixed with water. A 12:12-h light:dark cycle was maintained in the animal colony. Sessions began at 12:45 a.m., during the middle part of the dark phase of the cycle.

The rats worked in eight similar lever boxes located in a separate room adjacent to the animal colony. The dimensions of four of the boxes were $23 \times 20 \times 21 \mathrm{~cm}$; those of the remaining four were $23 \times 20 \times 28 \mathrm{~cm}$. The floor consisted of 17 or 18 parallel stainless steel bars. The roof and the side walls were acrylic; the front and back walls were aluminum. Each box contained a stainless steel lever on the front wall. The lever, which measured $5 \times 1 \mathrm{~cm}$, projected $1.5 \mathrm{~cm}$ into the box, $8 \mathrm{~cm}$ above the floor. The front lip of the lever was rounded. The force needed to depress the lever was $15 \mathrm{~g}$. A pellet dispenser (various manufacturers) delivered the food reinforcernent (one 45-mg sugar pellet, Bio Serv Mix T101) to a food tray beneath and to the side of the lever on the front wall. A small lamp (General Electric 1155X) mounted on the roof of each box was the light stimulus. The sound stimulus was a broad-band increase in the noise level from 65 to $69 \mathrm{~dB}$ (A scale) produced by a speaker located behind the back wall of each box. Each box contained a ventilation fan that helped mask outside noise. A computer controlled the experimental events, recorded the data, and, every 100 msec, checked the microswitch. A response was recorded when the microswitch was closed (lever down) and then opened (lever up).

Procedure. All rats were given training on a discrete-trials, variable-interval schedule signaled by light for half the rats and by sound for the other half. Once each trial started (i.e., the light or sound came on), food was primed (i.e., the next response was reinforced) with a probability of .066 every $1 \mathrm{sec}$. After food was primed and the rat made a response, the rat was given a single pellet of food and the light or sound was turned off. The ITIs were either short or long, and each duration was equally likely and selected randomly. Short and long ITIs were initially a minimum of 20 and $200 \mathrm{sec}$, respectively (Days 1-3), but were later changed to a minimum of 10 and $300 \mathrm{sec}$ (Days 4-24). After this minimum duration, a small random duration was added to each ITI. Each random duration ended, and the next trial began, with a probability of .05 (Days 1-3) or .2 (Days 4-24) every second. Although the ITIs were 10 and $300 \mathrm{sec}$ plus this small random duration, for conciseness they are referred to as the 10-sec ITI and the 300-sec ITI, respectively, in this and all subsequent experiments. The small random addition was employed so that the rats could not precisely predict when the next trial would begin. The sessions lasted either $4 \mathrm{~h}$ (Days 1-3) or $5 \mathrm{~h}$ (Days 4-24). The rats were placed in the experimental cages about $6 \mathrm{~h}$ prior to the start of each session, and were removed about $3 \mathrm{~h}$ after each session.

Data taken. The duration of each trial before food was primed and the number of responses on each trial before food was primed were recorded. To minimize the effect of behaviors that were not of central concern to this study (e.g., if a rat fell asleep during a session, then the subsequent absence of responding could at most only affect the recorded duration of one trial until food was primed), only data obtained prior to the priming of food were recorded. Trial 
duration and responding were recorded as a function of the duration of the five preceding ITIs. For example, total responses and trial duration were recorded separately for trials preceded by the ITI sequence short-long-long-long-short. Therefore, each trial was categorized as one of 32 possible types. In addition, the response rate during the variable part of the ITI was recorded. To minimize the role of warm-up effects, data were not collected from the first 10 trials of each session.

Data ansiysis. For each rat, an average response rate for a given trial or set of trials was calculated by dividing the total number of responses made for a trial type over days by the total duration of those trials. For example, consider the first 3 days of this experiment, when trials were separated by $20-\mathrm{sec}$ and 200 -sec ITIs. If, on trials preceded by five consecutive short ITIs, a rat made 20 , 30 , and 25 responses on 3 days, respectively, and the total durations of these trials were 40,60 , and $50 \mathrm{sec}$, respectively, then the rat's response rate for these days would be $.5 \mathrm{resp} / \mathrm{sec}(20+30$ $+25=75$ responses, $40+60+50=150 \mathrm{sec}, 75 \mathrm{resp} / 150 \mathrm{sec}$ $=.5 \mathrm{resp} / \mathrm{sec}$ ). Averages over all rats, for each phase, are biweights of the average for each rat with a weighting constant of 9 iterated 6 times (for a description and justification of the biweight, see Mosteller \& Tukey, 1977).

Analyses of variance (ANOVAs) treated the rat as a random factor and the other factors as fixed. Tests of significance were based on the square root of the average of each rat's response rate. Squareroot transforms were chosen to help normalize the data. All $p$ values are two-tailed.

\section{Results}

Figure 1 shows daily response rates separately for trials immediately preceded by a short ITI and for trials immediately preceded by a long ITI. The response rate was consistently higher after the short ITI. When the short and long ITIs were more similar (20- vs. 200-sec ITI during Days 1-3), short ITIs resulted in higher response rates on subsequent trials than did long ITIs, although the difference was not reliable. Figure 2 shows response rates as a function of the preceding five ITIs when the short ITI was $10 \mathrm{sec}$ and the long ITI was $300 \mathrm{sec}$ (Days 4-24). The most recent ITI determined the response rate, whereas the preceding four ITIs had no effect. A rat $\times$ most recent ITI $\times$ second most recent ITI $\times$ third most recent ITI $\times$ fourth most recent ITI $\times$ fifth most recent ITI ANOVA showed that the main effect of ITI was significant for the most recent ITI $[F(1,7)=6.1, p<.05]$, and that none of the other four ITI positions had a significant effect $\left[F_{\mathrm{s}}(1,7) \leq 1.2\right]$.

The results given in Figures 1 and 2, and in the other figures presented here, are heavily averaged. However, they are representative of individual responding. For example, the response rate of any rat after the 10-sec ITI was greater than the response rate of any rat after the 300 sec ITI.

Responding was minimal during the ITI. Throughout the experiment, the median number of responses was 0 and the mean was always less than $1 \mathrm{resp} / \mathrm{min}$. This low level of responding was found in the other six experiments reported here (i.e., the median was always 0 ). Accordingly, responding during the ITI is reported only for Experiment 1.

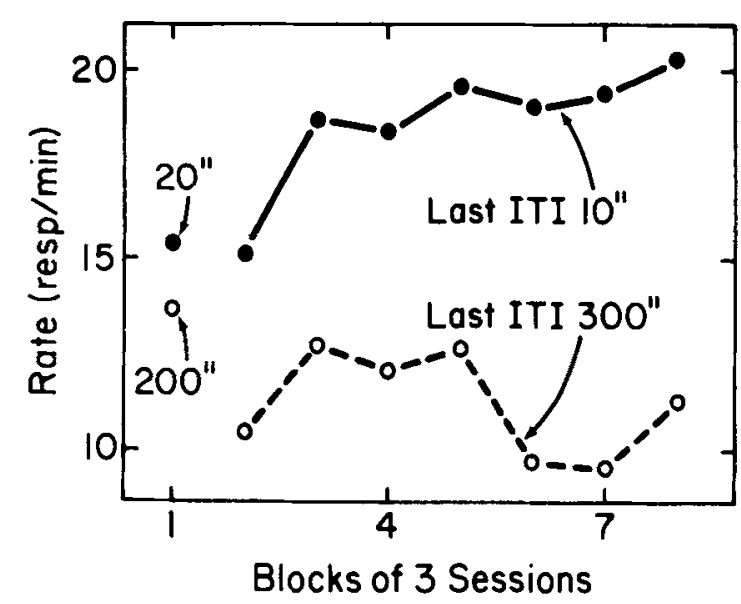

Figure 1. Experiment 1: Response rates plotted over sessions separately for trials preceded by short ITIs (20-sec first point, 10 sec remaining points) and long ITIs (200-sec first point, 300-sec remaining points). The response rate was higher on trials preceded by short ITIs (filled circles, solid lines) than on trials preceded by long IILs (open circtes, broken lines). Each point represents the average for three consecutive sessions computed with an ADDFTT analysis (McNeil \& Tukey, 1975) of the rat $x$ session matrix after the data for each three sessions were combined, as descibed in the text.

\section{Discussion}

There was a clear effect of ITI duration: there was more responding on trials immediately preceded by a 10 -sec ITI than on trials immediately preceded by $300-\mathrm{sec}$ ITIs. This effect was not cumulative; it was complete after just one ITI.

The results were opposite to what one might expect on the basis of most of the theories and findings outlined in the introduction; longer ITIs usually result in an increase in responding. The only work that had predicted lower responding after long ITIs was the arousal work of Killeen $(1979,1982)$. However, although this arousal theory might be used to explain the increased response rate after short ITIs, the fact that the effect observed here was not cumulative is inconsistent with current theories. Arousal theory as stated by Killeen claims that arousal should build up over trials when reinforcers are presented as frequently as they were in the present study. For example, when one group of pigeons was given food every $30 \mathrm{sec}$ and a second group was given food every $120 \mathrm{sec}$, arousal was not only greater for the group given the 30sec ITIs, but arousal for both groups was greater after five reinforcers than after just one reinforcer (Killeen et al., 1978).

\section{EXPERIMENT 2 SAME RESULTS WITH A BETWEEN-SUBJECTS REPLICATION?}

In Experiment 1, there was less responding on trials preceded by long ITIs than on trials preceded by short ITIs. Experiment 2 was designed to see if this result could 


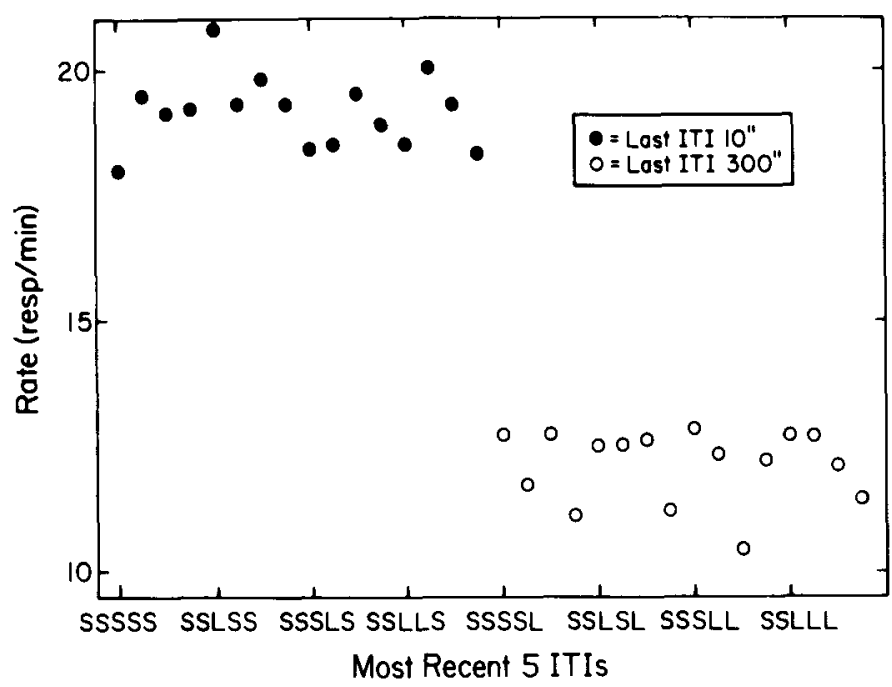

Figure 2. Experiment 1: Response rates plotted separately for each combination of five ITI durations that preceded each trial. The number and recency of 300-sec IT/s increase from left to right (the leftmost point represents the response rate on trials preceded by five consecutive 10-sec ITIs, and the rightmost point represents trials preceded by five consecutive 300 -sec ITIs). When the most recent ITI was 10 sec (filled circles), the response rate was higher than when the most recent ITI was $300 \mathrm{sec}$ (open circles). Each point represents the average, companted with an ADDFTT analysis (McNeil \& Tukey, $1975)$ of the rat $x$ trial-type matrix after the data for all days with 10- and 300-sec ITIs were combined, as described in the text. Letters along the abscissa refer to the durations of the last five ITIs, with LLLSS, for example, indicating that the two most recent ITls were short and the three ITIs before those two were long.

be repeated with a between-subjects design. The findings discussed earlier that support arousal theory were all obtained from studies that had used between-groups designs. Furthermore, many of the studies described in the introduction that reported increases in responding after longer ITIs, including those on behavioral contrast (see Williams, 1983) and autoshaping, used between-groups designs. In Experiment 1, because both short and long ITIs were used in a single session, within-session comparisons of long and short ITIs were possible. If the results of Experiment 1 could be repeated with a between-groups design in which these comparisons could not be made, then we could conclude that the comparisons were not necessary for the basic effect.

Experiment 2 was similar to Experiment 1 in that the rats were trained on a discrete-trials, variable-interval schedule. Unlike Experiment 1, the rats were first trained only with intermediate ITIs of $60 \mathrm{sec}$. After training, they were assigned to two groups: one that received only 300 sec ITIs and another that received only 10-sec ITIs. Later, the group-to-ITI-duration assignments were reversed.

\section{Method}

Subjects and Apparatus. The subjects were 19 male albino rats (Charles River CD). They had all previously been used in a procedure that consisted of standard classical conditioning trials intermingled with duration-discrimination trials in which they were trained to press one lever after 3 sec of light or sound and a second lever after $12 \mathrm{sec}$ of light or sound (Roberts \& Holder, 1985). The animal colony and apparatus were the same as those used in Experiment 1 , except that two additional lever boxes were used, making for a total of 10 .

Procedure. Baseline (Days 1-14). All rats were given training on a discrete-trials, variable-interval schedule as in Experiment 1. ITIs were a minimum of $60 \mathrm{sec}$, and, after this minimum duration ended, the next trial started with a probability of .2 every second. The subjects were run in two shifts during the light phase of the light:dark cycle. The first shift started at about 9:30 a.m., and the second at about 3:30 p.m. Each session lasted 2 h.

Testing (Days 15-39). The rats were assigned to two groups: Group 300-10, whose ITIs were a minimum of $300 \mathrm{sec}$, and Group 10-300, whose ITIs were a minimum of $10 \mathrm{sec}$. After the minimumduration ITI, ITIs ended with a probability of .2 every second for both groups. Each group was given 21 trials each session. Both groups remained in the experimental boxes for the same amount of time each session. Approximately half the rats from each group were run in each shift.

Reversal (Days 40-59). This phase was the same as the testing phase except that the ITI-to-rat assignments were reversed. Rats in Group 10-300 were given 300-sec ITIs, and rats in Group 30010 were given 10 -sec ITIs.

Data taken and Data analysis. The data were recorded and averages calculated as in Experiment 1. Between-groups tests of significance used standard mean-based $t$ tests. All $p$ values are twotailed.

\section{Results}

Figure 3 shows response rates over days for each group. During both testing and reversal, there was no clear difference between the response rates of the two groups. For Group 300-10, when the ITI was $300 \mathrm{sec}$, the response 


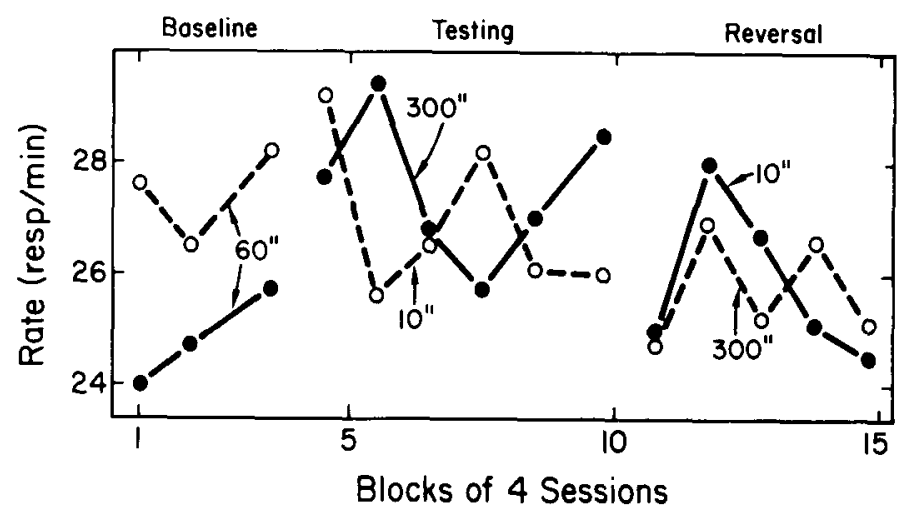

Figure 3. Experiment 2: Response rates plotted over sessions separately for rats that received 300-sec ITIs during testing and 10-sec ITIs during reversal (filled circles, solid lines) and 10-sec ITIs during testing and 300-sec ITIs during reversal (open circles, broken lines). Response rate did not change across phases for each group when the ITI duration was changed. Similarly, response rate did not differ within phases between each group, even though the ITI duration for each group was different. Each point represents the average for four consecutive sessions computed as described in the caption for Figure 1.

rate was $25 \mathrm{resp} / \mathrm{min}$, and when the ITI was $10 \mathrm{sec}$, the response rate was $28 \mathrm{resp} / \mathrm{min}$. For Group $10-300$, when the ITI was $300 \mathrm{sec}$, the response rate was $22 \mathrm{resp} / \mathrm{min}$, and when the ITI was $10 \mathrm{sec}$, the response rate was 21 resp/min. A between-phases comparison showed no change in the response rate despite the change in ITI $[t(10)<1]$. There were no statistically reliable betweengroups differences within any of the three phases $[t(18)<1]$. Two additional tests were performed. First, the values from the baseline phase were subtracted from the values from the testing phase in order to minimize individual rat differences that might have obscured any differences between the groups. This was important because small differences between groups were apparent during the baseline phase. Second, the values from the reversal phase were subtracted from the values from the testing phase in order to maximize the possibility of finding a difference between the groups. These two additional tests did not show reliable differences between the two groups $[t \mathrm{~s}(18) \leq 1.1]$.

\section{Discussion}

Unlike the within-subjects comparisons of Experiment 1 , in this experiment, there was no effect of ITI on responding, which suggests that the effect of ITI duration on responding observed in Experiment 1 required some sort of within-session comparison of ITI. However, the failure to find the effect could have been due to increased variance from the between-groups design resulting from individual differences. This seems unlikely because of the strength of the effect observed in Experiment 1. In Experiment 1, the lowest response rate of any rat after the 10-sec ITI was higher than the highest response rate of any rat after the 300 -sec ITI. Because the difference in responding in Experiment 1 was large even when between-rats comparisons were made, if the same effect existed in Experiment 2, then increased variance should not have obscured it. However, even when individual differences were minimized by subtracting the baselinephase response rates from the testing-phase response rates, no differences between groups were found.

The 21 total trials for each session ended sooner for the group that received 10-sec ITIs than for the group that received 300-sec ITIs. However, the group that received 10-sec ITIs remained in the experimental cages until the other group finished. Any potential differences produced by the different ITIs, such as the level of context conditioning, may have been obscured by the fact that US density in the experimental apparatus was the same for both groups (i.e., overall session length and total number of USs were the same). However, since the effect of ITI duration was apparent after one trial in Experiment 1, the effects in Experiment 2 should have been apparent with this procedure as well. Furthermore, in Experiment 1, despite the fact that the rats were in the experimental cages for about $6 \mathrm{~h}$ prior to the start of each session and $3 \mathrm{~h}$ after each session, the effect of the ITI on responding was not obscured. Therefore, it seems unlikely that the failure in this experiment to find differences in responding after different ITIs was because the two groups of rats had the same overall density of trials and food. Furthermore, since the effect of ITI duration on response rate was complete after one trial in Experiment 1, it seems less likely that the failure to observe this effect in Experiment 2 was attributable to differences in session length.

Although there were several differences between Experiment 2 and the five further experiments reported here, we think the important difference is the use of a between-subjects design as opposed to a withinsubjects design. 


\section{EXPERIMENT 3 RANGE OF THE EFFECTIVE ITI DURATIONS}

Experiment 1 showed that when a within-subjects design is used, ITI duration affects barpressing on subsequent trials. Experiment 3 was designed to replicate this result with naive rats, in an attempt to see more clearly the development of the effect, and to measure the effect of intermediate-duration ITIs. As in Experiment 1, the rats were trained to press a lever on a discrete-trials, variable-interval schedule. The trials were separated by a minimum of 10- or 300-sec ITIs. Intermediate ITIs first of $40 \mathrm{sec}$, then of $80 \mathrm{sec}$, and finally of $160 \mathrm{sec}$ were later added.

There may be an upper limit to the ITI durations to which rats are sensitive. In other words, there may be a point at which all durations greater than this point result in similar responding on subsequent trials. For example, rats might not be able to distinguish ITI durations over $60 \mathrm{sec}$. If this is true, then responding should be different on trials preceded by 40 - and 300 -sec ITIs, but the same on trials preceded by 80 - and 300 -sec ITIs.

Determining the upper limit of the ITI duration that differentially affects rats will help narrow down the possible explanations for the effect of the ITI on responding. One possible explanation for the effect is that after eating a food pellet, a rat stays close to the lever for the duration of the short ITI. The rat might stay close to the lever to search the food tray next to the lever for more food or because it anticipates the next trial in a short time since half of the trials occur after a 10-sec ITI. If responding is a function of distance from the lever, then the size of the experimental cages should limit the range of the effect. It seems unlikely to us that a rat, which can move the length of the cage in less than $1 \mathrm{sec}$, would be a greater distance from the lever after a 300-sec ITI than after a 160 -sec ITI. Therefore, if distance from the lever is the important factor, the response rate should be equally low after 160 -sec and 300-sec ITIs.

\section{Method}

Subjects and Apparatus. The subjects were 12 naive male albino rats (Charles River CD) that were 90 days old at the start of the experiment. The apparatus was the same as that used in Experiment 2.

Procedure. Pretraining (Days 1-3). Ten rats were given 2 days of magazine and response training. Throughout the session, the light and sound were always off. Free food was given an average of once every $2 \mathrm{~min}$ until 50 responses were made. In addition to the free food, the first 50 responses were all reinforced with a single pellet; $50 \%$ of the second 50 responses were reinforced; and, after the 100 th response, $25 \%$ of all responses were reinforced. On Day 3, 2 additional rats were given magazine and response training for one session. From the 12 rats, the 10 with the highest response rates were selected for the remainder of the experiment. The pretraining sessions, which started at 12:45 a.m. during the dark part of the light:dark cycle, lasted $2 \mathrm{~h}$.

Training (Days 4-59). All rats were given training on a discretetrials, variable-interval schedule, as in Experiment 1. The ITIs were either 10 or $300 \mathrm{sec}$, as in Experiment 1 . The sessions were $5 \mathrm{~h}$ long.

Intermediate ITIs (Days 60-95). This phase was the same as the training phase except that, in addition to 10 - and 300-sec ITIs, there were ITIs of an intermediate duration. The minimum intermediateduration ITIs were first $40 \mathrm{sec}$ (Days 60-67), then $80 \mathrm{sec}$ (Days 68-75), then $160 \mathrm{sec}$ (Days 76-83), and finally $40 \mathrm{sec}$ again (Days 84-95). After each minimum intermediate-duration ITI, the trials started with a probability of .2 every second. Short, long, and intermediate ITIs were all equally likely.

Data taken and Data analysis. The duration of each trial and the number of responses on each trial before food was primed were recorded as a function of the duration of the preceding ITT. One of the 10 rats used for the main part of the experiment developed a tumor midway through the experiment; his data are not included in the reported results.

Data analysis was the same as in Experiment 1 except that all $p$ values are one-tailed because, on the basis of Experiment 1, the direction of the results was predicted to show that increasing ITIs result in lower response rates.

\section{Results}

Figure 4 shows response rates as a function of the preceding ITI. At first, response rates following 10 - and 300-sec ITIs increased at similar rates. However, during the last $\mathbf{4 0}$ days of training, as in Experiment 1, the asymptotic response rate was higher on trials preceded by short ITIs $[t(6)=2.97, p<.05]$. This remained true when each intermediate ITI duration was presented $[t s(6)>3.02, p s<.05]$.

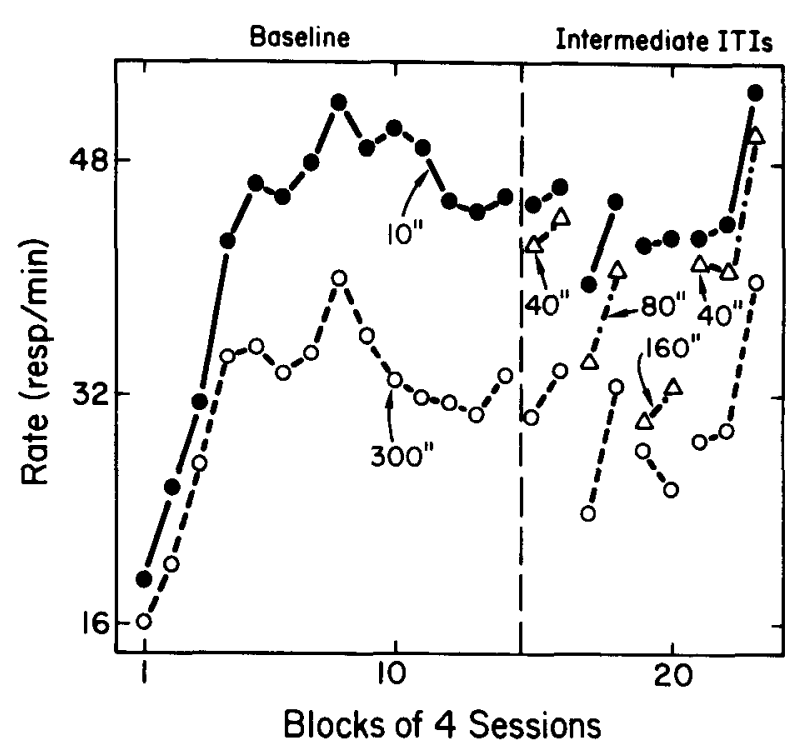

Figure 4. Experiment 3: Response rates plotted over sessions separately for trials preceded by 10-sec MIs (filed circles, solid lines), 300-sec IT/s (open circles, broken lines), and intermediate ITIs (open triangles, dotted lines). Response rate was higher on trials preceded by $10-\mathrm{sec}$ ITIs than on trials preceded by $300-\mathrm{sec}$ ITIs. Response rate on trials after intermediate ITIs was in between that after 10-sec and $300-\mathrm{sec}$ ITIs, with $40-\mathrm{sec}$ ITIs resulting in a greater response rate than $80-\mathrm{sec}$ ITIs and $80-\mathrm{sec}$ ITIs resulting in a greatear response rate than 160-sec ITIs. Each point represents the average for four consecutive sessions computed as described in the caption for Figure 1. 
Figure 4 also shows that the response rate on trials preceded by an intermediate ITI was always lower than on trials preceded by $10-\sec$ ITIs, but higher than on trials preceded by 300 -sec ITIs. Also, the response rate on trials preceded by intermediate ITIs decreased as the intermediate ITI was increased. When intermediate ITI durations were first introduced, the response rate on trials following 40- and 80-sec ITIs was closer to the response rate on trials following 10 -sec ITIs [ts $(6)<1.59$, ps $>.05$ ] than on those following 300 -sec ITIs $[\operatorname{ts}(6)>3.9$, $p s<.005]$. When the intermediate duration of the ITI was increased to $160 \mathrm{sec}$, the response rate on trials following this ITI was lower than the response rate following 10 -sec ITIs $[t(6)=3.7, p<.05]$ but higher than the response rate following 300 -sec ITIs $[t(6)=2.9$, $p<.05$ ]. Similarly, when the intermediate ITI duration was decreased back to $40 \mathrm{sec}$, the response rate after 40 sec ITIs was lower than the response rate after 10-sec ITIs $[t(6)=2.1, p<.05]$ but higher than the response rate after 300 -sec ITIs $[t(6)=5.9, p<.005]$.

Between-phases comparisons were consistent with the within-phase comparisons just described. Increasing the duration of the intermediate ITIs resulted in lower responding on subsequent trials. When the intermediate ITI was increased from 40 to $80 \mathrm{sec}$, and from 80 to $160 \mathrm{sec}$, the response rate on trials immediately following these ITIs decreased [ts $(6)>3.0, p s<.05]$.

\section{Discussion}

The rats were able to distinguish the intermediate from the short and long ITIs, which indicates that whatever the limits on their sensitivity to ITI duration, the upper bound is greater than $160 \mathrm{sec}$ and the lower bound is less than $40 \mathrm{sec}$. This conclusion is based on the finding that 160 sec ITIs and 40-sec ITIs produced response rates different from both $10-$ and $300-\mathrm{sec}$ ITIs.

As discussed in the introduction to this experiment, if the distance between the rat and the lever was responsible for the difference in responding after 10 - and 300-sec ITIs, then it is unlikely that five different ITIs would produce five different levels of responding. If the size of the cage were divided into five equal parts (the number of different ITIs used in this experiment), then a difference of 2 in., or $1.5 \mathrm{in}$. in the smaller boxes, would have to result in different response rates. These distances seem too small to account for different response rates. Furthermore, after the rat moved away from the lever, there is little reason to think that it would move further away after a 300-sec ITI than after a 160-sec ITI (a rat can traverse the cage in $1 \mathrm{sec}$ ).

\section{EXPERIMENT 4 WHAT EVENTS MARK THE START OF THE ITI?}

Experiments 1 and 3 showed that the duration of the ITI affected barpressing. Although this finding indicated that the rats were sensitive to the duration of the ITI, it was not possible to determine what events marked the start of the ITI. In both experiments, either the trial stimulus (e.g., CS offset) and/or the presentation of food could have marked the start of the ITI, since both events were presented at the same time. Experiment 4 was designed to determine whether the stimulus, the food, or both events marked the ITI's start.

As in Experiments 1 and 3, the rats were trained to press a lever on a discrete-trials, variable-interval schedule. The trials were separated by a minimum of 10 or $300 \mathrm{sec}$. During some of the 300 -sec ITIs, food was presented $10 \mathrm{sec}$ before the end of the ITI; during some of the others, the CS was presented alone and then turned off $10 \mathrm{sec}$ before the next trial. If the start of the ITI was marked by the presentation of food, then responding after food presented $10 \mathrm{sec}$ before the trial should be similar to that on trials preceded by 10 -sec ITIs. Similarly, if the start of the ITI was marked by the CS, then the CS presented alone $10 \mathrm{sec}$ before the trial should result in responding similar to that on trials preceded by $10-\mathrm{sec}$ ITIs.

Determining what events mark the start of the ITI may help determine the nature of the process responsible for the difference in responding after different ITIs. For example, as noted in Experiment 1, the effect of different ITIs may be the result of arousal. On each trial, the CS and/or the food increases arousal, which dissipates over time during the ITI. This arousal is greatest immediately after a trial, and the higher the arousal during a trial, the higher the response rate. If this arousal interpretation is correct, then either food or the CS alone presented $10 \mathrm{sec}$ before the next trial could increase arousal and, therefore, increase responding. Overmier and Schwarzkopf (1974) showed that stimuli paired with either food or shock could increase instrumentally conditioned responding in a way consistent with an arousal explanation. A second explanation that makes the same prediction for this experiment is based on whether or not a memory trace is in working memory. Suppose that each trial creates a memory trace of a CS-food association in some current working memory. The probability that the trace will remain in working memory decreases over time. Therefore, the likelihood of the trace being in working memory is greater $10 \mathrm{sec}$ after a trial than $300 \mathrm{sec}$ after. Responding is greater when the trace is in working memory. In this experiment, when the CS or the food alone is presented, the memory of the CS-food association is reinstated and, therefore, is strong $10 \mathrm{sec}$ later when the next trial starts. Accordingly, responding should be increased by food or the CS alone $10 \mathrm{sec}$ before the next trial.

Alternatively, presenting the CS alone, but not food alone, during the ITI may result in an omission effect. An omission effect is found when animals are trained on a fixed-interval schedule with food, and the omission of food at the end of one interval results in an overall increase in the response rate during the next interval (Stad- 
don \& Innis, 1969). If an omission effect is present, then presenting the CS alone, but not food alone, should result in increased responding on the next trial.

\section{Method}

Subjects and Apparatus. The nine rats from Experiment 3 were used, as well as 1 naive rat given 1 day of response-rate training as in Experiment 3. The apparatus and animal colony room were the same as those used in Experiment 3.

Procedure. The procedure was similar to that of Experiment 3. The rats were trained on a discrete-trials, variable-interval schedule, as in Experiment 1. The ITIs were either 10 or $300 \mathrm{sec}$, as in Experiment 1. In addition to 10- and 300-sec ITIs, there were food and CS-alone ITIs. On food ITIs, the ITI was the same as the long ITI except that $10 \mathrm{sec}$ before the end of the minimum-duration ITI, a single pellet of food was given to the rat independently of responding. On CS-alone ITIs, the ITI was the same as the long ITI except that the CS was presented alone for $15 \mathrm{sec}$ (the average trial duration) and was turned off $10 \mathrm{sec}$ before the minimum ITI ended. Of the total ITIs, $40 \%$ were $300 \mathrm{sec}, 40 \%$ were $10 \mathrm{sec}, 10 \%$ were food, and $10 \%$ were CS alone. There were a total of six sessions, each lasting $5 \mathrm{~h}$. The sessions started at 12:45 a.m., during the dark part of the light:dark cycle.

Data taken and Data analysis. The data were recorded and analyzed as in Experiment 3.

\section{Results}

This experiment reproduced the basic result of Experiments 1 and 3. The results are illustrated in the left panel of Figure 5. The response rate was higher following the 10 -sec ITI than following the 300-sec ITI $[t(6)=5.0$, $p<.005$ ]. The response rate on trials following food ITIs was similar to that following 10 -sec ITIs $[t(6)<2.12$, $p>.05]$ and much greater than that following $300-\mathrm{sec}$ ITIs $[t(6)>4.8, p<.01]$. The response rate on trials following CS-alone ITIs was actually greater than the response rate following 10 -sec ITIs $[t(6)>3.2$, $p<.05]$. When only the first 3 days were considered, rates after CS-alone and food ITIs were similar to rates after 10 -sec ITIs [ts $(6)<1.74, p s>.05]$, but much higher than rates after 300 -sec ITIs $[t s(6)>3.6$, $p s<.05]$.

\section{Discussion}

As in the previous experiments, the response rate was lower on trials preceded by 300 -sec ITIs than on trials preceded by 10 -sec ITIs. However, if food or the CS alone was presented during a $300-\mathrm{sec}$ ITI, 10-sec before the next trial, then the response rate on this next trial was similar to the response rate on trials preceded by $10-\mathrm{sec}$ ITIs. This result suggested that the rats marked the start of the ITI from both food and the CS. After the food and CS-alone ITIs, presumably barpressing would have been similar to that following 300-sec ITIs if the food and CS alone had been omitted. The CS alone and food therefore resulted in the rats' resetting their measurement of the ITI and starting over again.

Although, with six sessions of training, the response rate was higher after CS-alone ITIs than after 10-sec ITIs, this was not true during the first three sessions. It is pos- sible that after several sessions, the rats learned that nonreinforced presentations of the CS signaled a reinforced trial after a short ITI. All nonreinforced presentations of the CS were followed by a reinforced trial after a short ITI. Although the time from the CS alone to the next trial was 10 sec plus a variable amount, this variable amount was small enough for the rats to be able to predict that the next trial would begin in a short time. This predictability may have allowed the rats to prepare for the next trial, which could have lowered the latency to the first response, resulting in a higher response rate (see Experiment 7). With additional sessions, the rats might have learned that unsignaled food also signaled a reinforced trial in $10 \mathrm{sec}$ and, therefore, the response rate might have been greater after food ITIs than after 10-sec ITIs. Experiment 6 examined more closely the role of predictability in determining the effect of the ITI duration.

The result that the CS alone presented $10 \mathrm{sec}$ before the next trial affected responding was consistent with an explanation based on the omission effect. Omitting expected food can increase the response rate on the next trial. However, the omission effect does not account for the result that the response rate was also higher after food was presented alone $10 \mathrm{sec}$ before the next trial.

Both the arousal and working-memory explanations outlined in this experiment's introduction are consistent with the increase in the response rate on trials preceded by food alone and on trials preceded by the CS alone. Food and signals for food increase arousal or increase the probability that a CS-food association is in working memory, which in turn increases the response rate. Experiment 5 was designed in part to help determine whether the working-memory or arousal explanation best describes the effect of ITI duration on responding.

\section{EXPERIMENT 5 EFFECT OF A NOVEL STIMULUS ON SUBSEQUENT RESPONDING}

Experiment 4 suggested that both a signal for food and food itself can mark the start of the ITI. Experiment 5 was designed to determine if a novel stimulus-a stimulus other than the one presented on the majority of trialscould also mark the start of the ITI. If the CS or food presented alone increases responding on a trial $10 \mathrm{sec}$ later by reinstating the CS-food association in working memory, then the presentation of the novel stimulus should not increase responding on a trial $10 \mathrm{sec}$ later. This failure to increase responding would be expected, since the novel stimulus has never been paired with the CS or food and so cannot reinstate a memory of the CS and food.

As in Experiments 1, 3, and 4, the rats were trained to press a lever on a discrete-trials, variable-interval schedule. The trials were separated by $10-$ or $300-\mathrm{sec}$ minimum ITIs. During some of the 300 -sec ITIs, a novel stimulus was presented for $15 \mathrm{sec}$ and then turned off $10 \mathrm{sec}$ before the next trial. If the rats measure ITI duration starting from the novel stimulus, then the novel stimu- 
lus terminating $10 \mathrm{sec}$ before the trial should result in barpressing similar to that on trials preceded by 10 -sec ITIs.

\section{Method}

Subjects and Apparatus. The subjects and apparatus were the same as those used in Experiment 4.

Procedure. The procedure was similar to that of Experiment 4 . The rats were trained on a discrete-trials, variable-interval schedule, as in Experiment 1. The modality-to-rat assignments were the same as in Experiment 4 . For example, if light was previously the trial stimulus, then it remained the trial stimulus. ITIs were either 10 or $300 \mathrm{sec}$, as in Experiment 1. In addition to 10- and 300-sec ITIs, there were novel-stimulus ITIs. With novel-stimulus ITIs, the ITI was the same as the long ITI except that a novel stimulus was presented alone for $15 \mathrm{sec}$ and turned off $10 \mathrm{sec}$ before end of the minimum-duration ITI. For the rats that had always received light, the novel stimulus was sound; for the rats that had always received sound, the novel stimulus was light. Of the total ITIs, $45 \%$ were $300 \mathrm{sec}, 45 \%$ were $10 \mathrm{sec}$, and $10 \%$ were novel stimulus. There were a total of nine sessions, each lasting $5 \mathrm{~h}$; the sessions started at 12:45 a.m., during the dark part of the light:dark cycle.

Data taken and Data analysis. The data were taken as in Experiment 3. All $p$ values are two-tailed except when 10 - and 300sec ITIs are compared, since, on the basis of the earlier work, the direction of the results was predicted (that longer ITIs would result in lower response rates). To determine the effect of a novel stimulus-which is no longer novel after extended presentationsonly the results of the first three sessions are considered here. However, the results would be similar if all nine sessions were included.

\section{Results}

The basic effect of ITI duration on the response rate was maintained. During the first three sessions, the asymptotic response rate was higher on trials following the 10 -sec ITI than on those following the 300 -sec ITI $[t(6)=5.0, p<.005]$. During the first three sessions, the novel stimulus was presented an average of 21 times to each rat. The response rate was slightly higher on trials preceded by the novel stimulus than on trials preceded by 10 -sec ITIs $[t(6)=4.7, p<.05]$. These results are displayed in the right panel of Figure 5. During the first session, when the novel stimulus was presented an average of seven times to each rat, the results were similar. On trials immediately after the novel stimulus, the response rate was similar to that after 10 -sec ITIs $[t(6)<1]$, but greater than after $300-\sec$ ITIs $[t(6)=1.6$, $2>p>1]$.

\section{Discussion}

The now-familiar finding that the response rate was higher after 10-sec ITIs than after 300-sec ITIs was repeated here. The new finding was that the response rate on trials preceded by a novel stimulus $10 \mathrm{sec}$ earlier was similar to the response rate on trials preceded by $10-\mathrm{sec}$ ITIs. This suggested that the novel stimulus was able to reset the measurement of the ITI. One previously discussed explanation states that responding is determined by whether or not the CS-food association is in working memory. Any event that reminds the rat of this association will reset the measuring of the ITI. This explanation seems unlikely, because a novel stimulus that has never

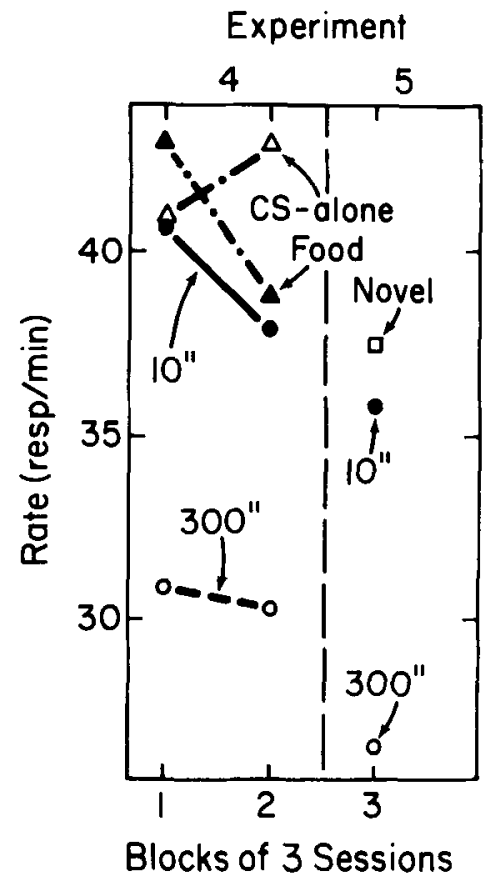

Figure 5. Experiments 4 and 5: Response rates plotted over sessions separately for trials preceded by 10-sec ITs (filled circles, solid lines), 300-sec ITIs (open circles, broken lines), CS-alone ITIs (open triangles, dotted line-left panel, Experiment 4), food ITIs (filled triangles, dotted lines-left panel, Experiment 4), and novel ITs (open square-right panel, Experiment 5). Response rate was high on trials $10 \mathrm{sec}$ after the $\mathrm{CS}$ alone, food, a novel stimulus, or a trial and low after 300-sec ITIs. Each point represents the average for three consecutive sessions computed as described in the caption for Figure 1.

been presented with the CS or food cannot remind the rat of a CS-food association, although it can reset its measuring of the ITI. A second explanation states that responding is a function of the level of arousal. Any event that increases arousal will reset the measuring of the ITI. If we assume that the novel stimulus increased arousal, then this arousal-based explanation is consistent with the findings reported here.

\section{EXPERIMENT 6 EFFECT OF A FAMILIAR STIMULUS ON RESPONDING}

Experiment 6 was designed to measure the effect of a familiar stimulus $10 \mathrm{sec}$ before a trial. After the effects of the novel stimulus were tested in Experiment 5, the formerly novel stimulus was presented many times in Experiment 6 without being reinforced. A stimulus that has been presented alone many times, so that it is familiar but not associated with a US, should have little effect on arousal. If responding in the procedure used in the experiments reported here depends on arousal, then presenting a familiar stimulus $10 \mathrm{sec}$ before the next trial should not change responding on that trial.

During the first phase of Experiment 6, a trial always followed the familiar stimulus by $10 \mathrm{sec}$. This phase was 
the same as in Experiment 5, except that the number of long ITIs with the previously novel stimulus was increased. It is possible that the familiar stimulus resets the measuring of the ITI, because the rats learned that it predicted when the next trial would start. In the next phase, the familiar stimulus did not predict as well when the next trial would occur. The trial after the familiar stimulus started $10,90,180$, or $275 \mathrm{sec}$ later. If the familiar stimulus reset the measuring of the ITI in the first phase because it was predictive, then when it is less predictive, it should be less likely to cause resetting.

\section{Method}

Subjects and Apparatus. The subjects and apparatus were the same as those used in Experiment 5, except that 1 of the 10 rats was experimentally naive. This rat was given 1 day of response training, as described in Experiment 3.

Procedure. Predictive 1 (Days 1-8). This phase was the same as in Experiment 5 , except that $50 \%$ of all ITIs were familiarstimulus ITIs (familiar-stimulus ITIs were the same as novel ITIs in Experiment 5, except that the stimulus was presented during half the total ITIs, so it was more familiar). For the rats that had always received light on the reinforced trials, the familiar stimulus was sound; for the rats that had always received sound, the familiar stimulus was light. Familiar-stimulus ITIs were employed to determine the influence of a familiar stimulus on the effect of the times between trials, and to make the originally novel stimulus familiar. The sessions, which lasted $5 \mathrm{~h}$, started at 12:45 a.m., during the dark part of the light:dark cycle.

Less predictive (Days 9-56). With familiar-stimulus ITIs, the familiar stimulus was presented for $15 \mathrm{sec}$ during the long ITls. The familiar stimulus was turned off $10,90,180$, or $275 \mathrm{sec}$ before the minimum $300-\mathrm{sec}$ ITI ended. Since the familiar stimulus was presented at varying times before the next trial, it was less predictive than in the Predictive 1 phase. In addition to familiarstimulus ITIs, there were CS ITIs, which were the same as familiarstimulus ITIs, except that the stimlus presented during the ITI was the one that was reinforced after 10 - and 300-sec ITIs. The familiar stimulus and the CS, when presented at intermediate times during long ITIs, were never reinforced. Of the total ITIs, 33\% were 300 sec and $33 \%$ were 10 -sec; $17 \%$ were familiar-stimulus and $17 \%$ were CS ITIs. During the familiar-stimulus and CS ITIs, each duration between the stimulus offset during the ITI and the end of the minimum ITI $(10,90,180$, or $275 \mathrm{sec})$ was equally likely.

Predictive 2 (Days 57-74). Familiar-stimulus ITIs were the same as those in the Predictive 1 phase; the familiar stimulus was always turned off $10 \mathrm{sec}$ before the next trial and, therefore, was predictive of when the next trial would occur. The CS on CS ITIs was still presented at varying times before the next trial. The proportions of trials, and therefore the average ITIs, were the same as during the Less predictive phase. The likelihood of each trial was the same as in the Less predictive phase.

Data taken and Data analysis. In addition to the data recorded as described in Experiment 4, response rates during the familiar stimulus and the CS alone on CS ITIs were measured.

All $p$ values are two-tailed except when 10 and $300-\sec$ ITIs were compared since, on the basis of the earlier work, the direction of the results was predicted. In order to study the effects at asymptote, the days included in the reported analysis are as follows: Predictive 1, all days; Less predictive, Days 21-56; Predictive 2, Days 66-74.

\section{Results}

Figure 6 shows that the basic effect remained: the response rate during each phase was higher following 10 -

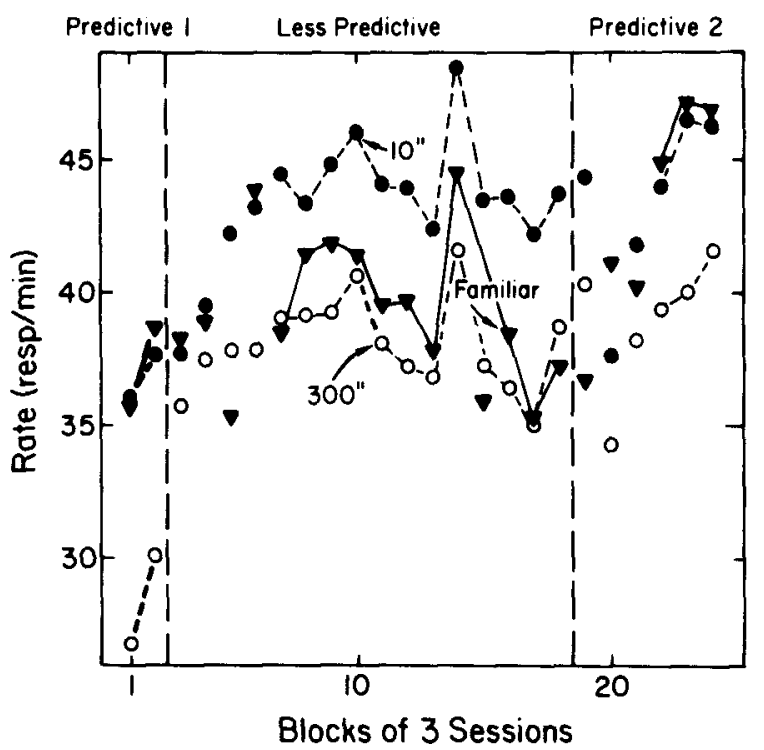

Figure 6. Experiment 6: Response rates plotted over sessions separately for trials preceded by 10 -sec ITIs (filled circles, dashed lines), 300-sec ITIs (open circles, dashed lines), and familiar ITIs (filled triangles, solid lines). Response rate was higher on trials preceded by 10-sec ITIs than on trials preceded by 300-sec ITIs. Response rate was high on trials $10-s e c$ after the familiar stimulus when the next trial was predicted (during Predictive 1 and 2) but was lower when the familiar stimulus was leas predictive (during Less predictive). Exch point represents the average for three consecutive sessions computed as described in the caption for Figure 1 . The points connected by lines were chosen by eye to show asymptotic performance. These points were the last 2 points of Predictive 1, the last 12 of Less predictive, and the last 3 of Predictive 2.

sec ITIs than following 300 -sec ITIs $[t s(6)>4.2$, $p s<.005$ ]. The most important new finding was that response rates on trials $10 \mathrm{sec}$ after the familiar stimulus were similar to rates after 10 -sec ITIs only during the Predictive 1 and 2 phases. During the Less predictive phase, the response rate on trials $10 \mathrm{sec}$ after the familiar stimulus was less than the response rate after 10-sec ITIs. These results are summarized in Table 1.

During the Predictive 1 and 2 phases, a reinforced trial always followed the familiar stimulus within about $10 \mathrm{sec}$. The effect of the now familiar stimulus was similar to its effect when it was novel in Experiment 5 . The response rate after the familiar stimulus was the same as the response rate after the $10-\sec \operatorname{ITI}[t(6)<1]$, but greater than the response rate after the $300-\sec$ ITI $[t(6)=3.9$, $p<.01]$. During the familiar stimulus, the rats rarely pressed the bar; the response rate was less than $1 \mathrm{resp} / \mathrm{min}$ for all rats.

During the Less predictive phase, the response rate on trials $10 \mathrm{sec}$ after the familiar stimulus was now reliably less than the response rate after 10 -sec ITIs $[t(6)=4.3$, $p>.01]$ and still greater than the response rate after 300 sec ITIs $[t(6)=4.0, p<.01]$.

The response rate on trials $10 \mathrm{sec}$ after the CS alone was always high. During both the less predictive and predictive 2 phases, the response rate after CS ITIs $10 \mathrm{sec}$ 
Table 1

Experiment 6: Rates (resp/min) as a Function of the Preceding ITI Preceding ITI

$\frac{10 \mathrm{sec}}{\text { Mean } S E} \frac{300 \mathrm{sec}}{\text { Mean } S E} \frac{\begin{array}{c}\text { Familiar } \\ (10 \mathrm{sec})\end{array}}{\text { Mean } S E} \frac{\begin{array}{c}C S \\ (10 \mathrm{sec})\end{array}}{\text { Mean } S E}$

\begin{tabular}{llllllllll}
\hline $\begin{array}{c}\text { Predictive } \\
\text { Days 1-8 }\end{array}$ & 35.7 & 7.6 & 27.0 & 5.8 & 34.7 & 7.9 & - & \\
$\begin{array}{c}\text { Less Predictive } \\
\text { Days 21-56 }\end{array}$ & 41.8 & 9.1 & 36.3 & 8.1 & 39.6 & 8.6 & 45.4 & 10.0 \\
$\begin{array}{c}\text { Predictive } \\
\text { Days 66-74 }\end{array}$ & 43.3 & 10.2 & 36.1 & 9.4 & 42.9 & 9.8 & 45.6 & 10.8 \\
\hline
\end{tabular}

Note-Values are biweights across the average response rates for the 10 rats. Response rates were calculated by separately adding across the indicated days the total responses during all trials preceded by each type of ITI and dividing by the total cumulative duration of the trials. The column labeled $10 \mathrm{sec}$ refers to trials preceded by 10 -sec ITIs, $300 \mathrm{sec}$ refers to trials preceded by 300 -sec ITIs, Familiar $(10 \mathrm{sec})$ refers to trials preceded $10 \mathrm{sec}$ earlier by the familiar stimulus, and CS (10 sec) refers to trials preceded $10 \mathrm{sec}$ earlier by the CS alone.

before the next trial was always greater than the response rate after 10 -sec ITIs $[t(6)>2.74, p<.05]$.

\section{Discussion}

Once again, the basic result that the response rate is higher on trials preceded by 10 -sec ITIs than on trials preceded by 300 -sec ITIs was repeated. In addition, it was found that a familiar stimulus did not reset the measuring of the ITI unless it consistently signaled that the next reinforced trial would begin in $10 \mathrm{sec}$. This finding is consistent with the idea that increases in arousal underlie increases in the response rate. When the familiar stimulus was always presented $10 \mathrm{sec}$ before the next trial, arousal would be high because the rat could learn that the next trial would begin in $10 \mathrm{sec}$. However, when the familiar stimulus did not signal when the next trial would begin, it would not increase arousal and, therefore, responding would not change.

Interestingly, the response rate was always high on a trial that was preceded $10 \mathrm{sec}$ earlier by a nonreinforced CS. This high response rate, $10 \mathrm{sec}$ after the nonreinforced CS, was observed even though the nonreinforced trials did not predict well when the next reinforced trial would occur. This suggests that the CS does not have to be highly predictive to reset the measuring of the ITI if the CS has been paired with a US. The increased response rate after a nonreinforced CS might be explained in terms of an omission effect or by assuming that stimuli paired with USs increase arousal.

\section{EXPERIMENT 7 DO RESPONSE LATENCIES ACCOUNT FOR THE ITI EFFECT?}

The results of Experiments 1 and 3-6 were opposite in direction to many findings previously discussed. Experiment 7 bascially repeated Experiment 1 , but in addition to the rate of barpressing, the latency to the first re- sponse was recorded. The difference in barpressing after 10 and 300-sec ITIs could have occurred because the rats pressed the bar at different rates throughout each trial or because the time to start barpressing differed after different ITIs. By recording latencies, the contribution of the time before the first response on each trial could be assessed. If associative strength is the same after long and short ITIs, the response rate during each trial should be the same once responding is initiated. However, if associative strength varies after different ITIs, the differences in response rates after 10 - and 300 -sec ITIs would not likely be completely accounted for in terms of response latency.

\section{Method}

Subjects and Apparatus. The subjects were 7 male rats (Charles River CD). Prior to this experiment, they had been trained to press the bar on a discrete-trials, variable-interval schedule with 60 -sec ITIs. The apparatus was the same as that used in Experiment 1.

Procedure. The procedure was the same as in Experiment 1 (Days 4-24) except that the experiment was run longer (36 days). Trial duration and responses were recorded as in Experiment 1. Additionally, latencies to the first response on trials preceded by five long or five short ITIs were recorded for Days 19-30. Response latencies had a cutoff; if the rat had not made a response on a trial before food was primed, latency for that trial was recorded as the time food was primed. Latencies are reported as means \pm standard error of the means. Data analysis was the same as in Experiment 1 except that, in addition to response rates, the square roots of the response latencies were analyzed. Latencies were transformed to square roots in order to help normalize the latency data. Analysis of the nontransformed data, although not reported, gave similar results.

\section{Results and Discussion}

Figure 7 shows the response rates over days as a function of the most recent ITI. Figure 8 shows response rates as a function of the order of the five preceding ITIs. The results were similar to those of Experiment 1: the response rate on trials immediately preceded by $300-\mathrm{sec}$ ITIs was lower than the response rate on trials preceded by 10 -sec ITIs, and only the most recent ITI affected response rate. A rat $\times$ most recent ITI $\times$ second most recent ITI $\times$ third most recent ITI $\times$ fourth most recent ITI $\times$ fifth most recent ITI ANOVA showed that the main effect of ITI was significant for the most recent ITI $[F(1,6)=9.1$, $p<.05]$ and that none of the other four ITI positions had a significant effect $[F \mathrm{~s}(1,6) \leq 2.8, p \geq .1]$.

The response rate may have differed because the rats pressed the lever throughout the trial at a lower rate when the last ITI was long. However, the results indicate that a major reason for the lower response rate was because the rat took longer to press the lever after a long ITI $(8.6 \pm .8 \mathrm{sec})$ than to do so after a short ITI $(5.9 \pm .7 \mathrm{sec})$. Once started, the response rate on all trials was similar. The latency to the first response was shorter for trials preceded by five short than for trials preceded by five long ITIs $[t(4)=7.05, p<.01]$. When the latency to the first response was subtracted from the duration of each trial and response rates were recalculated, the response rate on trials preceded by five short ITIs was $26 \mathrm{resp} / \mathrm{min}$ and 


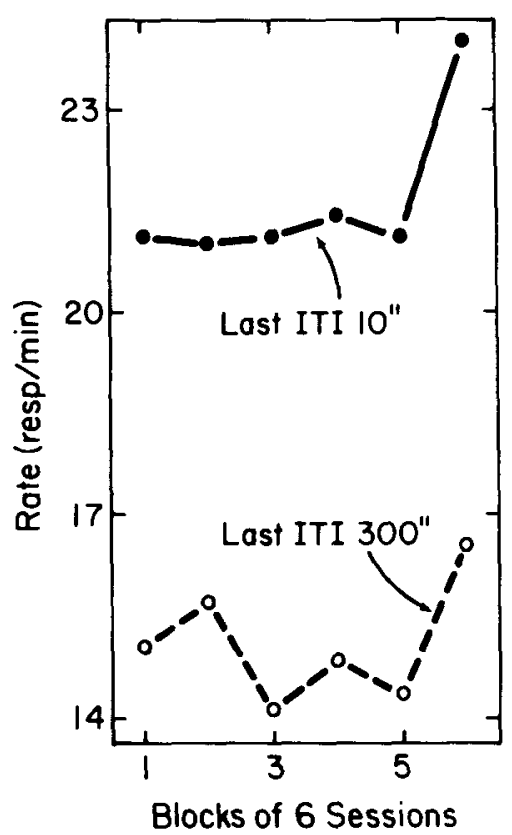

Figure 7. Experiment 7: Response rates plotted over sessions separately for trials preceded by 10-sec ITIs and 300-sec ITIs. Response rate was higher on trials preceded by 10-sec ITIs (filled circles, solid lines) than on trials preceded by 300-sec ITIs (open circles, broken lines). Each point represents the average for six consecutive sessions computed as described in the caption for Figure 1.

on trials preceded by five long ITIs was $24 \mathrm{resp} / \mathrm{min}$ $[t(4)<1]$.

Experiment 7 repeated the basic effect with rats that were first trained with 60 -sec ITIs. This suggests that the failure to observe the basic effect in Experiment 2 was not because the rats were originally trained with 60 -sec ITIs.

\section{GENERAL DISCUSSION}

This series of experiments shows that the duration of the ITI can influence the asymptotic barpressing of rats. The response rate was consistently higher on trials after short ITIs than on trials after long ITIs when both ITIs were presented during the same session (Experiments 1, 3-7). However, when the different ITIs occurred during different sessions, no difference in response rates after different ITIs was found (Experiment 2). The withinsession difference in response rate could largely be accounted for by different latencies to the first response rather than by different rates of responding (Experiment 7). The effect of ITI on responding appears to be complete after only one ITI and does not accumulate over ITls (Experiments 1 and 7). As intermediate ITIs increased from 40 to 80 to $160 \mathrm{sec}$, the response rate decreased, indicating that whatever the mechanism that produced the effect of ITI duration on responding, it distinguishes $160 \mathrm{sec}$ from $300 \mathrm{sec}$ (Experiment 3). Both food, the CS, and a novel stimulus presented $10 \mathrm{sec}$ before a trial produced response rates similar to those produced after a 10-sec ITI (Experiments 4 and 5). A familiar stimulus reset the ITI only when it was highly predictive of when the next trial would occur (Experiment 6).

The increase in the response rate after a short ITI is opposite to what one frustration theory (Amsel \& Roussel, 1952) and one conditioning theory (Gibbon \& Balsam, 1981; Jenkins et al., 1981) would predict. These theories claim that performance will increase as the average time between reinforcers increases. Of course, these theories were not designed to account for the ITI effect reported here. The difference in responding during the ITI and trials indicates that the rats learned a discrimina-

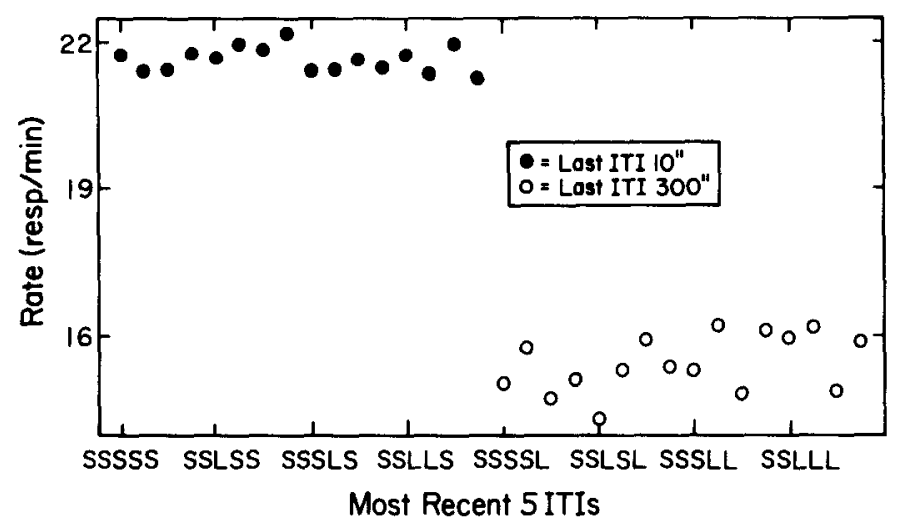

Figure 8. Experiment 7: Response rates plotted separately for each combination of five ITI durations that preceded each trial (see caption for Figure 2). When the most recent ITI was $10 \mathrm{sec}$ (filled circles), response rates were higher than when the most recent ITI was 300 sec (open circles). Each point represents the average for all 36 days computed as described in the caption for Figure 2. 
tion. When discriminations are formed, the frustration effect is abolished (Amsel \& Ward, 1965; Nevin \& Shettleworth, 1966), and, therefore, one would not expect Amsel's frustration theory to apply here. The work that contributed to the conditioning theory used an autoshaping procedure; measured acquisition, not asymptotic responding; used a between-subjects design; and used classical, not instrumental, conditioning. However, since these two theories do account for the effect of ITI in other situations, it is interesting to note how they fail to predict the results reported here. The most obvious failure is that the response rate was not higher after long ITIs than after short ITIs.

One attempt to account for the basic effect of ITI duration found here was by hypothesizing that the rats were further away from the lever after 300-sec ITIs than after 10 -sec ITIs. This difference in distance would account for the different latencies to press the bar after different ITIs that were found in Experiment 7. However, this explanation seems unlikely for two reasons: (1) Differences of less than 2 in. would have to be sufficient to result in different response latencies after different ITIs, and (2) there is no reason to think that the rats would be further from the lever after $300 \mathrm{sec}$ than after $160 \mathrm{sec}$. Furthermore, this explanation would need to be complicated in order to account for the failure to find the basic result with a between-subjects design.

A second way of accounting for the results reported here was based on a working-memory hypothesis. This hypothesis accounts for the result that shorter ITIs result in shorter response latencies by assuming that response latency reflects the probability of the CS-US association being in working memory; if the association is in working memory, the latency to initiate barpressing will be less. The association is in working memory immediately after the CS and/or the US, and the probability of the association remaining in working memory decreases with time. Therefore, the probability of the association being in working memory is greater after a short-ITI than after a long ITI. This idea successfully accounts for the basic result, as well as other findings reported here. For example, the CS alone and food alone reset the ITI by reinstating the association in working memory. However, this working-memory hypothesis has difficulty with the finding that a novel stimulus-a stimulus that one would not expect to reinstate the memory trace-can reset the ITI. Also, this hypothesis would need to be complicated in order to explain why the between-subjects procedure did not repeat the basic effect.

A third explanation is that responding reflects the degree to which the next trial is predicted. When the trial is predicted, latency to initiate barpressing is short. One advantage of this account is that it explains the finding that a familiar stimulus increases the response rate only when it is a strong predictor of the next trial. The predictiveness explanation could account for the finding that the response rate decreased as intermediate ITIs increased from 40 to $160 \mathrm{sec}$, if one assumes that predictiveness decreases as the time interval increases (Experiment 3 ). Predictiveness fails to explain why a novel, and therefore nonpredictive, stimulus affected barpressing, unless one assumes that the novel stimulus was predictive and produced the effect after being presented only seven times. Furthermore, the predictiveness explanation does not readily account for the failure to observe the basic effect with the between-subjects design.

A fourth way of explaining the basic effect is based on extinction of responding during the ITI. Responses during ITIs are not reinforced. More responses should $\alpha$ cur during longer ITIs, and, therefore, extinction should be greater, perhaps resulting in greater latencies after longer ITIs. However, responding was so low during the ITI for all experiments (the median was 0 ) that it seems unlikely that ITI responses could determine the effect.

A fifth attempt to account for this study's results was by invoking a hypothesis based on arousal. One arousal hypothesis (Killeen, 1979, 1982) suggests that changes in arousal can affect responding; the greater the arousal, the greater the response rate. Arousal is increased by the US, the CS, novel stimuli, and stimuli associated with the CS and the US. Arousal decreases over time when these events do not occur. The experiments reported here are not tests of the arousal hypothesis, because arousal was estimated on the basis of the results, not measured independently. For example, suppose the novel stimulus had failed to increase the response rate. The conclusion could then have been that the novel stimulus did not change the arousal responsible for changes in latencies, and the arousal hypothesis would have remained intact. However, on the basis of the results of Experiment 6that a familiar stimulus resets the ITI when it is predictive but not when it is less predictive-the arousal hypothesis can be a little better judged. An example of a test might be based on the prediction that a stimulus will first reset the ITI when it is paired with food but not later when it is extinguished. This idea is consistent with the finding, from Experiment 6, that the response rate increased on trials preceded $10 \mathrm{sec}$ earlier by the CS alone. The CS alone was not highly predictive of when the next trial would occur, but it still reset the ITI, probably because it was paired on other trials with the US.

The results reported here are not easily explained by replacing the term arousal with the term attention. Mackintosh (1975) suggested that stimuli that are reliable signals for reinforcement are better attended to than stimuli that do not signal important events. Perhaps stimuli that increase attention-for example, those with associative strength-decreased response latency in the present series of experiments. This explanation correctly predicts the finding that the familiar stimulus in Experiment 6 reset the measuring of the ITI only when it was a good signal for the next reinforced trial. However, this version of the 
attention explanation does not simply account for why the between-subjects design of Experiment 2 failed to show the basic result.

Arousal, as used here, is a vague term that seems to lack explanatory power. However, the type of arousal hypothesized here as possibly being responsible for the changes in responding after different ITIs has several empirically demonstrable properties: (1) It dissipates quickly enough for 10- and 40-sec ITIs to be distinguished, yet slowly enough for what is left after $160 \mathrm{sec}$ differs from what is left after $300 \mathrm{sec}$; (2) it is not cumulative-that is, it is complete after one trial; and (3) it may require some sort of within-in session comparison of ITIs, since the response rate does not differ between groups given different ITIs. These last two properties distinguish it from the arousal invoked by current models (Killeen, 1979, 1982).

In conclusion, although several possible explanations of the ITI effect reported here were considered, none seems completely satisfactory. Each explanation, at best, accounted for only some of the findings. It is possible that different mechanisms accounted for different effects. For example, changes in responding on a trial preceded by a nonreinforced CS may be accounted for by an omission effect, whereas changes after a novel stimulus may be accounted for by arousal theory. Although we would prefer to explain our results with a single mechanism, this may not be possible here.

\section{REFERENCES}

ALLEN, C. M. (1980). Patterns of activity and food oriented behavior induced by schedules of water reinforcement. Unpublished master's thesis, Arizona State University, Tempe, Arizona.

Amsel, A. (1967). Partial reinforcement effects on vigor and persistence. In K. W. Spence \& J. T. Spence (Eds.), The psychology of learning and motivation (pp. 1-65). New York: Academic Press.

AmSEL, A., \& Roussel, J. (1952). Motivational properties of frustration: I. Effect on a running response of the addition of frustration to the motivational complex. Joumal of Experimental Psychology, 43, 363-368.

AMSEL, A., \& WARD, J. S. (1965). Frustration and persistence: Resistance to discrimination following prior experience with the discriminanda. Psychological Monographs, 79(4, Whole No. 597).

BLOOMFiELD, T. M. (1967). Behavioral contrast and relative reinforcement frequency in two multiple schedules. Journal of the Experimental Analysis of Behavior, 10, 151-158.

DAvis, M. (1970). Effects of interstimulus interval length and variability on startle response habituation in the rat. Joumal of Comparative \& Physiological Psychology, 72, 177-192.

DOMJAN, M. (1980). Effects of intertrial interval on taste-aversion learning in rats. Physiology \& Behavior, 25, 117-125.

Gibbon, J., Baldock, M. D., Locurto, C., Gold, L., \& Terrace, H. S. (1977). Trial and intertrial durations in autoshaping. Journal of Experimental Psychology: Animal Behavior Processes, 3, 264-284.

Gibron, J., Balsam, P. (1981). Spreading association in time. In C. M. Locurto, H. S. Terrace, \& J. Gibbon (Eds.), Autoshaping and conditioning theory (pp. 219-253). New York: Academic Press.

HolDER, M. D., \& RoBerTs, S. (1985). Comparison of timing and clas- sical conditioning. Joumal of Experimental Psychology: Animal Behavior Processes, 11, 172-193.

JENKINS, H. M. (1984). Time and contingency in classical conditioning. In J. Gibbon \& L. Allan (Eds.), Timing and time perception (pp. 242-253). New York: New York Academy of Sciences.

Jenkins, H. M., BARnes, R. A., Barrera, F. J. (1981). Why autoshaping depends on trial spacing. In C. M. Locurto, H. S. Terrace, \& J. Gibbon (Eds.), Autoshaping and conditioning theory (pp. 255 384). New York: Academic Press

KILLEEN, P. R. (1979). Arousal: Its genesis, modulation, and extinction. In M. D. Zeiler \& P. Harzem (Eds.), Advances in analysis of behavior: Vol. I. Reinforcement and the organization of behavior (pp. 31-78). New York: Wiley.

KilleEN, P. R. (1982). Incentive theory. In D. J. Bernstein (Ed.), Nebraska Symposium on Motivation, 1981: Response structure and organization (pp. 169-216). Lincoln: University of Nebraska Press.

Killeen, P. R., Hanson, S. J., Osborne, S. R. (1978). Arousal: Its genesis and manifestation as response rate. Psychological Review, 85, $571-581$

MACKINTOSH, N. J. (1975). A theory of attention: Variations in the associability of stimuli with reinforcement. Psychological Review, 82, 276-298.

MACKINTOSH, N. J., LITTLE, L., LoRD, J. (1972). Some determinants of behavioral contrast in pigeons and rats. Leaming \& Motivation, $3,148-161$.

MCNeIL, D. R., TuKEY, J. W. (1975). Higher-order diagnosis of two-way tables, illustrated on two sets of demographic empirical distributions. Biometrics, 31, 487-510.

Mosteller, F., TukeY, J. W. (1977). Data analysis and regression. Reading, MA: Addison-Wesley.

Nevin, J. A., Shetrleworth, S. J. (1966). An analysis of contrast effects in multiple schedules. Journal of the Experimental Analysis of Behavior, 9, 305-315.

Overmier, J. B., \& SCHWARZKopf, K. H. (1974). Summation of food and shock based responding. Learning \& Motivation, 5, 42-52.

Peeke, H. V. S., \& Peeke, S. C. (1972). Habituation, reinforcement and recovery of predatory responses in two species of fish (Carassius auratus and Macropodus opercularis). Animal Behaviour, 20. 268-273

ROBERTS, S., HOLDER, M. D. (1985). Effects of classical conditioning on an internal clock. Journal of Experimental Psychology: Animal Behavior Processes, 11, 194-214.

RoтнкоPF, E. Z. (1955). Distribution of practice and the temporal decay of response-produced stimuli. Joumal of Experimental Psychology, 49, 33-38.

Staddon, J. E. R., \& INNIS, N. K. (1969). Reinforcement omission on fixed-interval schedules. Joumal of the Experimental Analysis of Behavior, 12, 689-700.

Stein, L., Sidman, M., Brady, J. V. (1958). Some effects of two temporal variables on conditioned suppression. Journal of the Experimental Analysis of Behavior, 1, 153-162.

TAus, S. E. . Hearst, E. (1970). Effects of intertrial (blackout) duration on response rate to a positive stimulus. Psychonomic Science, 19, 265-266

Terrace, H. M., Gibbon, J., Farrell, L., \& Baldock, M. D. (1975) Temporal factors influencing the acquisition and maintenance of an autoshaped keypeck. Animal Learning \& Behavior, 3, 53-62.

WILLIAMS, B. A. (1983). Another look at contrast in multiple schedules. Joumal of the Experimental Analysis of Behavior, 39, 345-384.

WiLton, R. N., \& Clements, R. O. (1971). Behavioral contrast as a function of the duration of an immediately preceding period of extinction. Journal of the Experimental Analysis of Behavior, 16, 425-428.

(Manuscript received June 4, 1987; revision accepted for publication October 21, 1987.) 